\title{
Article \\ Level of Murine DDX3 RNA Helicase Determines Phenotype Changes of Hepatocytes In Vitro and In Vivo
}

\author{
Olga Sergeeva ${ }^{1, *} \mathbb{\infty}$, Tatiana Abakumova ${ }^{1}$, Ilia Kurochkin ${ }^{1}$, Renata Ialchina ${ }^{1}\left(\mathbb{D}\right.$, Anna Kosyreva ${ }^{2} \mathbb{D}$, \\ Tatiana Prikazchikova ${ }^{1}$, Varvara Varlamova ${ }^{1}$, Evgeniya Shcherbinina ${ }^{1}$ and Timofei Zatsepin ${ }^{1,3}$ \\ 1 Skolkovo Institute of Science and Technology, Skolkovo, 121205 Moscow, Russia; \\ T.Abakumova@skoltech.ru (T.A.); I.Kurochkin@skoltech.ru (I.K.); renatayalchina@gmail.com (R.I.); \\ t.prikazchikova@skoltech.ru (T.P.); Varvara.Varlamova@skoltech.ru (V.V.); \\ Evgeniia.Shcherbinina@skoltech.ru (E.S.); t.zatsepin@skoltech.ru (T.Z.) \\ 2 Research Institute of Human Morphology, 117418 Moscow, Russia; kosyreva.a@list.ru \\ 3 Department of Chemistry, Lomonosov Moscow State University, 119992 Moscow, Russia \\ * Correspondence: o.sergeeva@skoltech.ru; Tel.: +7-926-388-0865
}

\section{check for} updates

Citation: Sergeeva, O.; Abakumova, T.; Kurochkin, I.; Ialchina, R.; Kosyreva, A.; Prikazchikova, T.; Varlamova, V.; Shcherbinina, E.; Zatsepin, T. Level of Murine DDX3 RNA Helicase Determines Phenotype Changes of Hepatocytes In Vitro and In Vivo. Int. J. Mol. Sci. 2021, 22, 6958. https://doi.org/ $10.3390 /$ ijms 22136958

Academic Editor: Vincenza Barresi

Received: 1 April 2021

Accepted: 23 June 2021

Published: 28 June 2021

Publisher's Note: MDPI stays neutral with regard to jurisdictional claims in published maps and institutional affiliations.

Copyright: (c) 2021 by the authors. Licensee MDPI, Basel, Switzerland. This article is an open access article distributed under the terms and conditions of the Creative Commons Attribution (CC BY) license (https:/ / creativecommons.org/licenses/by/ $4.0 /)$.

\begin{abstract}
DDX3 RNA helicase is intensively studied as a therapeutic target due to participation in the replication of some viruses and involvement in cancer progression. Here we used transcriptome analysis to estimate the primary response of hepatocytes to different levels of RNAi-mediated knockdown of DDX3 RNA helicase both in vitro and in vivo. We found that a strong reduction of DDX3 protein ( $>85 \%$ ) led to similar changes in vitro and in vivo-deregulation of the cell cycle and Wnt and cadherin pathways. Also, we observed the appearance of dead hepatocytes in the healthy liver and a decrease of cell viability in vitro after prolonged treatment. However, more modest downregulation of the DDX3 protein (60-65\%) showed discordant results in vitro and in vivosimilar changes in vitro as in the case of strong knockdown and a different phenotype in vivo. These results demonstrate that the level of DDX3 protein can dramatically influence the cell phenotype in vivo and the decrease of DDX3, for more than $85 \%$ leads to cell death in normal tissues, which should be taken into account during the drug development of DDX3 inhibitors.
\end{abstract}

Keywords: RNA therapy; transcriptome; RNA helicase; cancer; liver

\section{Introduction}

Recent progress in the consolidation of systems biology, high-throughput methods and bioinformatics has significantly promoted drug development. Early R\&D stages are crucial for success in clinical trials as thorough in vitro and in vivo evaluation of new molecules at the preclinical stage provides a solid basis and a margin of safety for the next steps [1,2]. Multiple omics techniques can provide exhaustive data on the changes of RNA, proteins, lipids and metabolites both in vitro and in vivo. Among these methods, transcriptome analysis increases our ability to evaluate the primary response of the cell to any external or internal signal both in vitro and in vivo, thus providing additional valuable information to common cellular assays and long-term animal studies.

RNA helicases are complex molecular motors that promote structural rearrangements in RNA and RNA-protein complexes and switch their activity [3]. DDX3 helicase is a member of the DEAD-box family, which is involved in many cellular processes, like transport and storage of mRNA [4,5], nuclear export of mRNA [4], mRNA splicing [6], modulation of transcription [7,8], translation [9,10], lipid hemostasis [11], regulation of endoplasmic reticulum stress [12], modulation of epigenetic modifications [13] and innate immune system activation [14]. Also, DDX3 is an essential factor for the replication of some viruses: CMV [15], HIV-1 [16], HCV [17], Japanese Encephalitis virus [18], Dengue virus [19], West Nile virus [20], vaccinia virus [21] and norovirus [22]. Being upregulated in some cancers and due to its contribution toward the replication of several viruses, DDX3 became an 
attractive target for the development of anticancer and antiviral therapeutics. The first DDX3 inhibitors were studied to target human immunodeficiency virus-1 [23,24]. Then, a number of nucleotide and nucleobase analogs, such as ring expanded nucleosides [25] and other small molecules that target the RNA-binding site [26], were developed as potent anticancer agents. Among them we want to emphasize a tricyclic diimidazodiazepine analog, known as RK-33, that was thoroughly studied due to its broad spectrum of antiviral and anticancer activities [27-29]. However, the participation of RNA helicases in almost all aspects of RNA metabolism increases the safety risks of inhibitors and requires thorough evaluation as multiple vital processes can be interfered with [30]. For example, DDX3 can act as an allosteric activator of casein kinase 1 (CK1) in the Wnt/ $\beta$-catenin pathway [31], TBK1/IKK $\varepsilon$ and IFN induction [32], NF-KB signal pathway [33], DNA-damage induced apoptosis [34], etc.

Here, we addressed the question of whether downregulation of DDX3 in the cell can result in significant dysregulation of key cellular processes in vitro (hepatocytes) and in the liver of healthy mice. We compared differential gene expressions after RNAi-mediated downregulation of DDX3 together with histological study. We found that a strong reduction of DDX3 protein $(>85 \%)$ in comparison to a control leads to similar changes in vitro and in vivo; we observed deregulation of the cell cycle and Wnt and cadherin pathways. As a result, we observed the appearance of dead hepatocytes in the liver and a decrease of cell viability in vitro after prolonged treatment. However, more modest downregulation of DDX3 protein (60-65\%) resulted in discordant results between gene expression in vitro and in vivo; in vitro data for both siRNAs were similar, while in vivo, the phenotype was different in comparison to data obtained for the strong reduction of DDX3 protein. These results demonstrate that the amount of DDX3 protein can dramatically influence the phenotype in vivo, which should be taken into account during drug development.

\section{Materials and Methods}

\subsection{Murine Cell Cultures}

Experiments were performed using a Hepa1-6 cell line (ATCC@CRL- 1830, VA, USA). Cells were cultured in DMEM/F12 medium (Gibco ${ }^{\text {TM }}$, Waltham, MA, USA), 10\% FBS $\left(\mathrm{Gibco}^{\mathrm{TM}}\right), 1 \%$ penicillin and $1 \%$ streptomycin $\left(10,000 \mathrm{U} / \mathrm{mL}\right.$, $\left.\mathrm{Gibco}^{\mathrm{TM}}\right)$ at $37^{\circ} \mathrm{C}$ and under $5 \% \mathrm{CO}_{2}$. Additionally, NIH/3T3 (ATCC@CRL- 1658) and Raw264.7 (ATCC®TIB-71) cells were used for the screening of DDX3 mRNA expression level. NIH/3T3 cells were cultured in DMEM/F12 medium (Gibco $\left.{ }^{\mathrm{TM}}\right), 10 \% \mathrm{FBS}\left(\mathrm{Gibco}^{\mathrm{TM}}\right), 1 \%$ penicillin and $1 \%$ streptomycin $\left(10,000 \mathrm{U} / \mathrm{mL}\right.$, Gibco $\left.{ }^{\mathrm{TM}}\right)$, while Raw264.7 were cultured in DMEM medium (Gibco $\left.{ }^{\mathrm{TM}}\right), 10 \%$ FBS $\left(\mathrm{Gibco}^{\mathrm{TM}}\right), 1 \%$ penicillin and $1 \%$ streptomycin $\left(10,000 \mathrm{U} / \mathrm{mL}\right.$, $\left.\mathrm{Gibco}^{\mathrm{TM}}\right)$ at $37^{\circ} \mathrm{C}$ and under $5 \% \mathrm{CO}_{2}$.

\section{2. siRNA Design and LNP Formulation}

We designed eight chemically modified siRNAs (Supplementary Materials Table S1) that targeted murine DDX3 mRNA (NCBI Genbank accession code NM_010028.3). siRNA were selected to avoid off-target binding based on the previously published rules [35-37]. In particular, siRNAs were ranked based on the number/positions of the mismatches in the seed region, mismatches in the non-seed region and mismatches in the cleavage site position. The resulting sequences were further filtered to avoid known miRNA motifs and immune stimulatory sequence motifs [38]. Chemical modification of siRNA increases stability against nucleases and further reduces immune response and off-target effects $[38,39]$. The potency and efficacy of siRNAs were studied by transfection using lipofectamine RNAimax (Thermo Scientific, Waltham, MA, USA) in Hepa1-6 cells followed by reverse transcription-quantitative PCR (RT-qPCR) analysis after $24 \mathrm{~h}$ (Supplementary Materials Figure S1C). The control siRNA targets the firefly luciferase gene (control). For the most active siRNAs (\#5 and \#7), IC50 values were determined. Cells were transfected with 12 concentrations of siRNA; each time, the concentration was decreased three times from $20 \mathrm{nM}$ to $0.04 \mathrm{pM}(20 \mathrm{nM}, 6 \mathrm{nM}, 2 \mathrm{nM}, 0.6 \mathrm{nM}$, etc.) and analyzed for $24 \mathrm{~h}$ by RT-qPCR. The 
IC50 value for siRNA was determined using the Curve Fitting protocol in Graph Pad Prizm version 7.0. Raw data from the RT-qPCR output were plotted against the logarithm of siRNA concentration. The data were normalized from the plateaus of nonlinear regression (Supplementary Materials Figure S1E,F).

The most efficient siRNA (\#5 and \#7) and control siRNA were formulated in lipid nanoparticles (LNPs) as previously described $[40,41]$. LNPs were dialyzed against PBS at pH7.4 in 20K MWCO cut off dialysis cassettes overnight and filtered through a PES syringe filter $(0.2 \mu \mathrm{m}$ pores). Particle size analysis was carried out using a Zetasizer Nano ZSP (Malvern Panalytical, Worcestershire, UK) according to the manufacturer's protocol (Supplementary Materials Table S3). siRNA entrapment efficiency was determined using the Quant-iT ${ }^{\mathrm{TM}}$ RiboGreen ${ }^{\circledR}$ reagent (Thermo Fisher Scientific R11491) as described earlier (Supplementary Materials Table S3) [42].

We checked the DDX3 mRNA and protein levels after the treatment with control siRNA (siLuc) in vitro and in vivo at the different timepoints (Supplementary Materials Figure S1G-I) and confirmed that the observed changes were not significant.

\subsection{Animal Care and Treatments}

All animal care and procedures were carried out according to the relevant National Institute of Health guidelines and were approved by the Bioethics Committee of the Institute of Developmental Biology (Moscow, Russia), where the animal study was performed. Balb/c mice (aged 6-8 weeks) were purchased from Stolbovaya Scientific Center of Biomedical Technologies of the Federal Medical and Biological Agency, Russia. Mice were housed at $22{ }^{\circ} \mathrm{C}$ using a 12 -h-light to 12 -h-dark cycle, fed ad libitum with regular rodent chow. Lipid nanoparticles with siRNAs were diluted in sterile saline and injected intravenously via the tail vein at the doses and regimes specified in the text (four mice per group). Mice were sacrificed and serum and liver samples were collected for analysis. Serum was collected by cardiac puncture, followed by centrifugation at $1700 \times g$ for $20 \mathrm{~min}$. Biochemical analysis was performed in Paster Laboratories (Moscow, Russia). Liver samples were snap-frozen, ground and portions of homogenized liver were used for further mRNA and protein analysis.

\subsection{Histological Analysis}

Liver samples were dehydrated by washing in increasing concentrations of ethanol, followed by xylene and paraffin processing in the automated system Tissue TEK VIP $5 \mathrm{Jr}$ (Sakura, Tokyo, Japan) and filled in blocks in the system Tissue TEK 5 (Sakura). Sections of 8-mm-thick were prepared using rotary microtome Microm GmbH HM 340 (Thermo Scientific, Germering, Germany) and stained with hematoxylin and eosin (H\&E) (Abcam, Cambridge, UK) according to the manufacturer's instructions.

\subsection{RNA Isolation and RT-qPCR}

Total RNA was isolated from the cell and liver tissue samples using TRIzol (Thermo Fisher Scientific, Waltham, MA, USA) according to the manufacturer's instructions. Then, $\sim 0.5-1 \mu \mathrm{g}$ of RNA was further treated with DNase I (Thermo Fisher Scientific) and supplied with RiboLock RNase Inhibitor $(40 \mathrm{U} / \mu \mathrm{L})$ to the final concentration $0.4 \mathrm{U} / \mu \mathrm{L}$. For RT-qPCR, the treated total RNA was used to synthesize cDNA using a Maxima First Strand cDNA Synthesis Kit (Thermo Fisher Scientific), followed by qPCR using a PowerUp ${ }^{\mathrm{TM}} \mathrm{SYBR}^{\mathrm{TM}}$ Green Master Mix (Thermo Fisher Scientific). PCRs were performed using the primers listed in Supplementary Materials Table S2. GAPDH mRNA was used as a control for the analysis of total RNA.

\subsection{Western Blotting}

Cell and tissue protein extracts were prepared from DDX3 KD and control cell and liver samples using RIPA Lysis and Extraction Buffer (Thermo Fisher Scientific) and supplied with $0.05 \%$ Triton X-100 (Helicon, Russia), 1 mM dithiothreitol (DTT) (Helicon, Russia), 
$0.2 \mathrm{mM}$ phenylmethylsulfonylfluoride (PMSF) (Sigma-Aldrich, St. Louis, MO, USA) and $1 \times$ Halt $^{\mathrm{TM}}$ Protease Inhibitor Cocktail (Thermo Fisher Scientific). The concentrations of the total protein in the lysates were determined by Bradford protein assay (Thermo Fisher Scientific). Cell extracts (15-50 $\mu \mathrm{g})$ were denatured by heating in the loading buffer at $95{ }^{\circ} \mathrm{C}$ for $10 \mathrm{~min}$ and separated by $10 \%$ SDS-polyacrylamide gel using PageRuler Prestained Protein Ladder as a marker (Thermo Fisher Scientific). Proteins were transferred to nitrocellulose membranes (Bio-Rad) using Mini Trans-Blot ${ }^{\circledR C}$ Cell and Criterion ${ }^{\mathrm{TM}}$ Blotter (Bio-Rad Laboratories Inc., Hercules, CA, USA) at $80 \mathrm{~V}$ for $40 \mathrm{~min}$ at RT. The remaining protein-binding sites of the nitrocellulose paper were blocked by immersion in TBS/Tween (10 mM Tris- $\mathrm{HCl}, 150 \mathrm{mM} \mathrm{NaCl}, 0.05 \%$ Tween 20, pH 7.5) with $5 \%$ bovine serum albumin (Sigma-Aldrich) at $4^{\circ} \mathrm{C}$ overnight. The blocked filter was incubated with primary antibody anti-DDX3 (A300-476A, Bethyl Lab, 1:3000 dilution), anti-cleaved PARP (ab32064, Abcam, 1:1000), anti- $\beta$-Actin (MA1-140, Thermo Fisher Scientific, 1:5000 dilution), anti-cleaved Caspase 3 (9664S, Cell Signaling, 1:1000), p- $\beta$-catenin Ser33/37/Thr41 (9561, Cell Signaling, 1:1000) and anti-GAPDH (14C10, Cell Signaling, 1:3000) for $1 \mathrm{~h}$ at room temperature. After washing with TBS/Tween, the appropriate secondary antibody was added and incubated for an additional $1 \mathrm{~h}$. Clarity ${ }^{\mathrm{TM}}$ Western ECL Blotting Substrates (Bio-Rad Laboratories Inc., CA, USA) were used to develop the blot images. We calculated the Western blot results using ImageJ software according to the standard protocol of the intensity measurement of the bands on the gel (https:/ /imagej.nih.gov/ij/docs/guide/user-guide.pdf (accessed on 1 June 2021)).

\subsection{Cell Viability Assay}

Hepa1-6 cells were plated into 48 -well plates in triplicates, $\sim 25 \times 10^{3}$ cells per well, and transfected with DDX3 siRNA \#5 and \#7 or control siRNA (final concentration $10 \mathrm{nM}$ ). The viability of the cells was measured at 24, 48, 72 and $96 \mathrm{~h}$ timepoints after initial transfection. Measurements were done using CellTiter 96®Aqueous One Solution Cell Proliferation Assay (MTS) (Promega, Madison, WI, USA), followed by $3 \mathrm{~h}$ incubation at $37^{\circ} \mathrm{C}$. Then, the fluorescent signal was measured using a Varioscan Microplate reader with a $490 \mathrm{~nm}$ filter (Thermo Fisher Scientific).

\section{8. mRNA-seq Data Processing and Analysis}

For transcriptome analysis, we used Hepa1-6 cells after four days of siRNA transfection; three replicates per experiment were used for each siRNA-\#5, \#7 and control. Total RNA was extracted using a TRIzol reagent (Thermo Fisher Scientific) according to the manufacturer's instructions. Also, we studied the total RNA sample from the liver tissue after 6 and 13 days of intravenous (IV) LNP-siRNA injections (\#5, \#7 and control). $\sim$ Six micrograms of total RNA (quantified using a NanoDrop ${ }^{\mathrm{TM}}$ One C Spectrophotometer (Thermo Fisher Scientific)) was fragmented using conditions optimized to result in an average of $200 \mathrm{nt}$ RNA fragments: incubation for $7 \mathrm{~min}$ at $95^{\circ} \mathrm{C}$ in RNA fragmentation buffer (100 mM Tris-HCl, $2 \mathrm{mM} \mathrm{MgCl2,} \mathrm{pH}$ 8.0). The fragmented RNA was purified by precipitation with $96 \%$ ethanol/3 M sodium acetate $(9: 1, \mathrm{v} / \mathrm{v})$, and $1 \mu \mathrm{g}$ of RNA (measured using a NanoDrop ${ }^{\mathrm{TM}}$ One C Spectrophotometer (Thermo Fisher Scientific) was used for an rRNA depletion reaction using a NEBNext rRNA Depletion Kit (NEB E6310L, New England Biolabs, MA, USA) according to the manufacturer's protocol. Then, the RNA solution was diluted with a $1 / 10$ volume of $3 \mathrm{M}$ sodium acetate; RNA precipitated with ethanol, and $300 \mathrm{ng}$ of RNA (measured using a NanoDrop ${ }^{\mathrm{TM}}$ One C Spectrophotometer (Thermo Fisher Scientific) were used for the sequencing library preparation with a NEBNext Ultra II Directional RNA Library Prep Kit for Illumina (NEB 7760, New England Biolabs), according to the manufacturer's protocol, and the resulting double-stranded cDNA was purified using AMPure XP magnetic beads (A63881, Beckman Coulter, Brea, CA, USA). Efficient concentrations of libraries were determined using RT-qPCR. Library quality (length distribution and the absence of primer-dimers) was assessed by Bioanalyzer 2100 (Agilent Technologies, Netherlands). Libraries were pooled in equal amounts and 
sequenced using a HiSeq 4000 (Illumina, San Diego, CA, USA) according to the manufacturer's protocol. Conversion to the fastq format and demultiplexing were performed using bcl2fastq2 software (Illumina, San Diego, CA, USA). In total, 27 samples (DDX3 KD and control KD samples) were sequenced, returning a variable number of paired reads. To map those samples, genome annotations were obtained from Ensembl, release 93. Paired-end reads were mapped using STAR version 2.5.3a [43] with default settings except for the following one: -quantMode GeneCounts. The resulting gene counts were further processed with R package DESeq2 [44], where it was further normalized using the RLE method. In order to take into account unwanted variation in the data, we obtained using the sva package [45] additional variables and introduced them into the design matrix to capture unwanted variations. The DESeq2 package was used for performing differential expression analysis based on the Wald test. We defined genes as differentially expressed if they passed the threshold: FDR $<0.05$. For those genes, we performed functional enrichment analysis using cluster Profiler [46]. The method enrichGO was used with BP/MF/CC ontology and $\mathrm{BH}$ correction for multiple testing; all genes that were expressed in the mouse were used as the background. Also, we used PANTHER (http:/ / pantherdb.org/ (accessed on 1 June 2021)) pathway analysis. To compare gene expression differences between siRNA \#5 and \#7 KD sets, we matched gene annotation in the same conditions. Then, we calculated log-fold changes between the gene expression levels in the cells at days 6 and 13 vs a control for both the siRNA \#5 and \#7 KD sets. To test whether log-fold change values agreed between the two KD experiments, we calculated the Pearson correlation coefficient and performed Fisher's exact test. Data were submitted to the Gene Expression Omnibus (GEO) (https: / / www.ncbi.nlm.nih.gov / geo / query / acc.cgi?acc=GSE178618 (accessed on 1 June 2021)) and will be accessible through accession number GSE178618.

\subsection{Statistical Analysis of the Experimental Data}

All diagrams are based on at least three independent experiments. Statistical data processing was performed using the GraphPad Prism software (version 8.3) (Graphpad Holdings, LLC, CA, USA) with a two-sample t-test, as well as a two-way ANOVA analysis of variance or repeated-measures ANOVA and Sidak t-test. The data were considered statistically significant at $p<0.05$.

\section{Results}

\subsection{Knockdown of DDX3 RNA Helicase in vitro}

We compared DDX3 mRNA levels in murine fibroblast (NIH/3T3), macrophage (RAW 264.7) and hepatoma (Hepa1-6) cell lines and confirmed the high level of mRNA in hepatoma cells (Supplementary Materials Figure S1A). In order to achieve silencing of DDX3 mRNA, we designed and synthesized eight siRNA and a control siRNA targeting the firefly luciferase gene (marked as Luc control) and screened them in Hepa1-6 cells (Supplementary Materials Figure S1B). For the two most efficient siRNAs (\#5 and \#7), we determined $\mathrm{IC}_{50}$ as the use of siRNA at low concentrations additionally decreases the possibility of off-target effects in vitro and in vivo. For siRNA \#5, the $\mathrm{IC}_{50}$ was $8 \pm 1.5 \mathrm{pM}$; for \#7, it was $3.2 \pm 0.4 \mathrm{pM}$ (Supplementary Materials Figure S1C,D). These potent siRNA were used in further studies. Also, we determined the level of DDX3 protein after 1, 2, 3 and 4 days of mRNA downregulation by siRNA \#5 in Hepa1- 6 cells and found that at day 4 the efficacy of DDX3 protein downregulation was $~ 80 \%$ (Supplementary Materials Figure S1E). The efficacy of DDX3 mRNA and protein downregulation by siRNA \#5 and \#7 in vitro was comparable with published results [47-49].

\subsection{Knockdown of DDX3 RNA Helicase in vivo}

First, we estimated DDX3 mRNA expression levels in different murine organs (Supplementary Materials Figure S1F). DDX3 RNA helicase was expressed in the heart, liver, kidneys, testicles, muscles and brain at a similar level, while in the spleen and lungs the mRNA expression was higher. Nevertheless, the DDX3 level in the liver was high 
enough to perform the study. Selected DDX3 siRNA were formulated into C12-200 lipid nanoparticles, previously validated in mice and nonhuman primates [50]. Due to their size (80-90 nm) and almost neutral charge, C12-200 siRNA-LNPs are preferably internalized by hepatocytes. Biodistribution of C12-200 siRNA LNP after intravenous injection in mice has been thoroughly assessed in previous studies, confirming liver-specific RNAi-mediated silencing [51].

We performed dose-response and mRNA recovery experiments for LNP-siRNA \#5 and \#7 to find an optimal regime for our study (Supplementary Materials Figure S2A,B). A single administration of $1 \mathrm{mg} / \mathrm{kg}$ LNP-siRNA \#5 and \#7 resulted in the profound knockdown of DDX3 mRNA in the liver with different efficacies. By $72 \mathrm{~h}$ post-injection, siRNA \#5 was more active and resulted in 75-80\% of mRNA downregulation, whereas siRNA \#7 was less active, resulting in $60-65 \%$ of mRNA downregulation in comparison to the DDX3 mRNA level in the liver without siRNA treatment (Supplementary Materials Figure S2A). Maximal mRNA and protein downregulation in the liver occurred two days after injection, followed by a slow recovery (Supplementary Materials Figure S2B,C). Hence, DDX3 silencing $>50 \%$ lasted for at least eight days.

After evaluation of DDX3 knockdown with the single dose of LNP-siRNA, we studied the toxicity of LNP-siRNA. Balb/c females received biweekly injections of LNPs loaded with siRNA $(1 \mathrm{mg} / \mathrm{kg})$ for three weeks. Analysis of the animal blood demonstrated that levels of ALT, AST, ALP and other key factors were not changed. Also, no significant weight changes or differences in the behavior of the mice were observed between the groups (Supplementary Materials Figure S3), indicating that long-term administration of LNP-siDDX3 was well tolerated.

Then, we studied the level of DDX3 mRNA at days 6, 8 and 13 for biweekly injections of $1 \mathrm{mg} / \mathrm{kg}$ LNP-siRNA (Figure 1A). We found that siRNA \#5 had higher activity in comparison to siRNA \#7, which correlated with the results in vitro (Figure 1B). Initial downregulation of DDX3 protein at day six was comparable: $\sim 75 \%$ for siRNA \#5 and $\sim 60 \%$ for siRNA \#7. However, the further trend for DDX3 protein level was different for siRNA $\# 5$ and \#7 (Figure 1C). At day eight, the efficacy of protein downregulation was still similar for both siRNAs (75-80\%, while more pronounced for siRNA \#5), but at day 13, the level of downregulation of DDX3 protein changed. For siRNA \#5, the DDX3 protein level dropped to $<15 \%$, while for siRNA \#7, it recovered to $\sim 35 \%$. As a result, we selected days 6 and 13 as timepoints for further gene expression analysis after the knockdown of DDX3 RNA helicase in vivo.

\subsection{Efficient Knockdown of DDX3 in the Murine Liver and Hepa1-6 Cells Induces Apoptosis of Hepatocytes}

To explore the effects of DDX3 downregulation during long-term administration ( 6 and 13 days) of LNP-siRNA in the murine liver, we performed a morphological study using hematoxylin-eosin (H\&E) staining of liver samples. According to our results, no pathological changes were observed in the Luc control group of Balb/c mice. Administration of more active siRNA \#5 resulted in minor focal accumulation of lymphocytes, neutrophils and histiocytes in hepatic lobules at day six. Also, all females had an increased number of non-epithelial cell elements along the beams. At day 13, the number of small foci of neutrophil infiltration increased, and also, we observed more binuclear hepatocytes. Two mice had individual dying hepatocytes and few minor foci of neutrophil infiltration in the stroma, along with focal necrosis. Administration of less active siRNA \#7 resulted in more soft effects. We still observed an increased number of binucleated hepatocytes, along with some accumulation of lymphocytes, neutrophils and histiocytes at days 6 and 13, but these changes were less significant than in the case of siRNA \#5 and no dying cells were observed (Figure 2A).

To reveal the driving force of hepatocyte death in the liver of DDX3 KD mice, we analyzed the level of cleaved caspase-3, a key player in apoptosis. We found the activation of caspase-3 after the administration of LNP-siRNA \#5 for 13 days, which correlates with the hepatocyte death detected by morphological study (Figure 2B). At the same time, 
the level of the cleaved caspase-3 was not increased after administration of less effective LNP-siRNA \#7.

To study the influence of DDX3 protein level on the survival of hepatocytes, we performed MTS assay using Hepa1-6 with DDX3 KD and control cells (Figure 3A). We observed a slight decrease in cell survival after DDX3 mRNA KD during the first three days. Hence, the behavior of the survival curve was similar for siRNA \#5 and \#7. However, at day four after administration, we observed the decrease in cell survival for siRNA \#5, while for siRNA \#7, no effects on cell survival were observed. Then, we measured the level of a hallmark of apoptosis, a cleaved form of PARP protein. We found that cleaved PARP was increased in the case of siRNA \#5 KD, while in the case of siRNA \#7, KD changes were more modest (Figure 3B). Activation of apoptosis in hepatocytes after prolonged siRNA \#5 administration can explain the decrease in cell survival. At the same time, a slower increase in cleaved PARP after siRNA \#7 administration did not activate cell apoptosis during the first three days of knockdown.

\subsection{Analysis of Gene Expression after Knockdown of DDX3 in vitro and in vivo}

RNA sequencing was used to profile the mRNA expression after RNAi-mediated downregulation of DDX3 RNA helicase in vitro and in vivo. We analyzed changes in mRNA expression at day four after DDX3 knockdown in vitro by more active siRNA \#5 and less active siRNA \#7. The same approach was used in vivo: we analyzed the transcriptome of the murine liver at days 6 and 13 after DDX3 KD by LNP-siRNA \#5 and \#7. Comparison of scatterplots of the changes of mRNAs expression levels revealed a huge difference between the phenotypes of DDX3 KD cells obtained with siRNA \#5 and \#7 in vitro and in vivo because many changes did not overlap (Figure $4 \mathrm{~A}$ ).

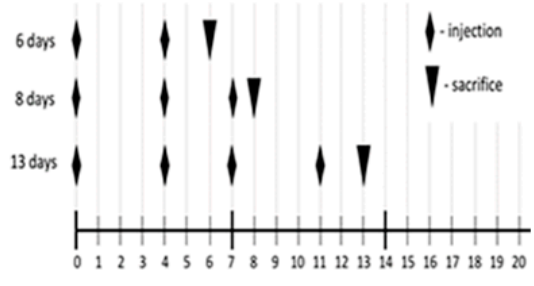

B.

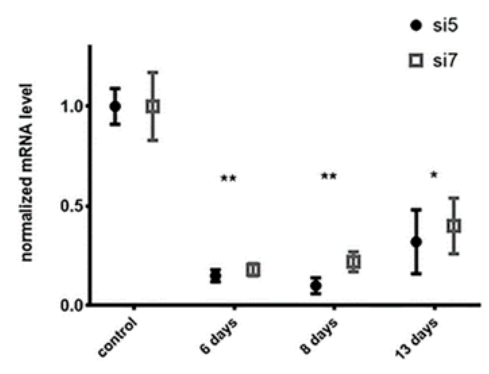

C.

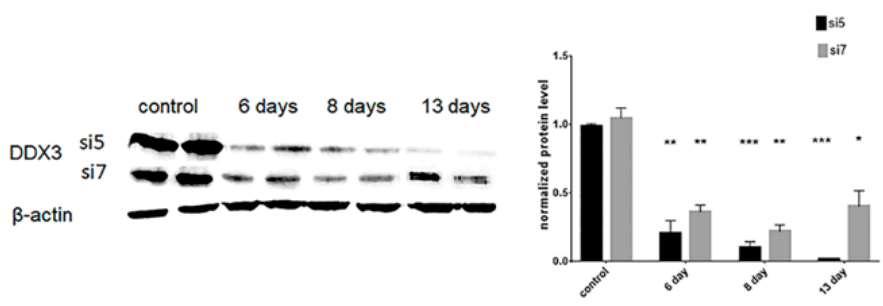

Figure 1. Knockdown of DDX3 in murine liver. (A) Schedule of LNP-siRNA injections in vivo. (B) RT-qPCR quantification of DDX3 mRNA recovery after single LNP-siRNA \#5 and \#7 IV injectionmRNA levels at days 6, 8 and 13. (C) Western-Blot analysis of DDX3 protein at days 6, 8 and 13 after multiple LNP-siRNA \#5 and LNP-siRNA \#7 injections according to schedule $1 \mathrm{~A} .{ }^{*} p<0.05,{ }^{* *} p<0.01$, *** $p<0.001$. 
A.

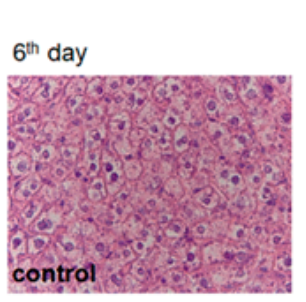

Infiltration of neutrophil,
lymphocytes and histiocyte

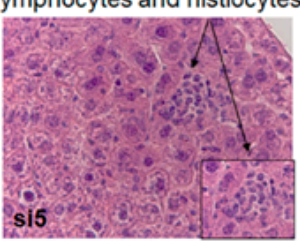

Binuclear hepatocytes
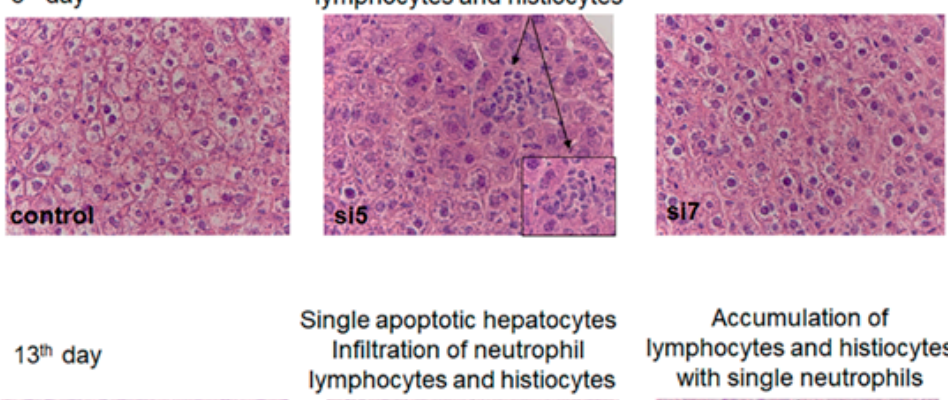

Accumulation of lymphocytes and histiocytes

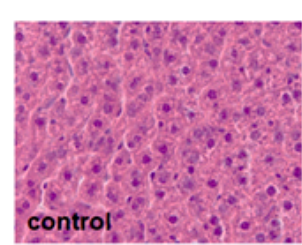
lymphocytes and histiocytes with single neutrophils

B.
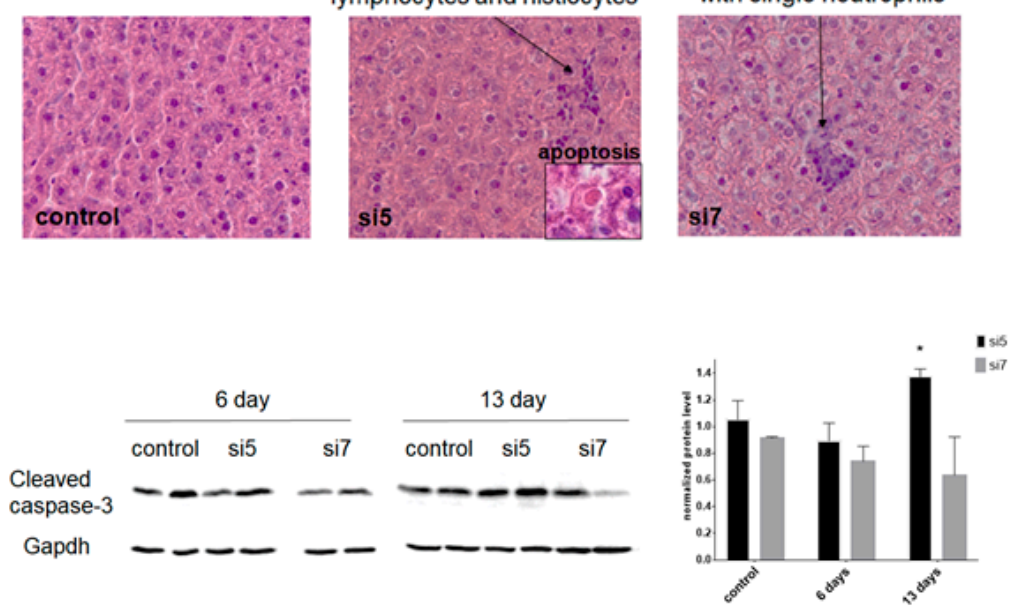

Figure 2. Characterization of murine liver phenotype after DDX3 knockdown. (A) Morphological analysis (H\&E staining) of liver samples after DDX3 knockdown with LNP-siRNA \#5 and \#7 at days 6 and 13. (B) Quantification of cleaved caspase-3 in DDX3 KD hepatocytes at days 6 and 13 after initial siRNA transfection (normalized to control cells). ${ }^{*} p<0.05$.

A.

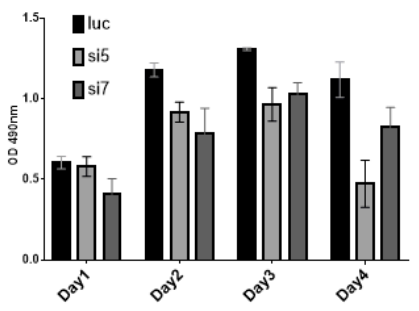

B.
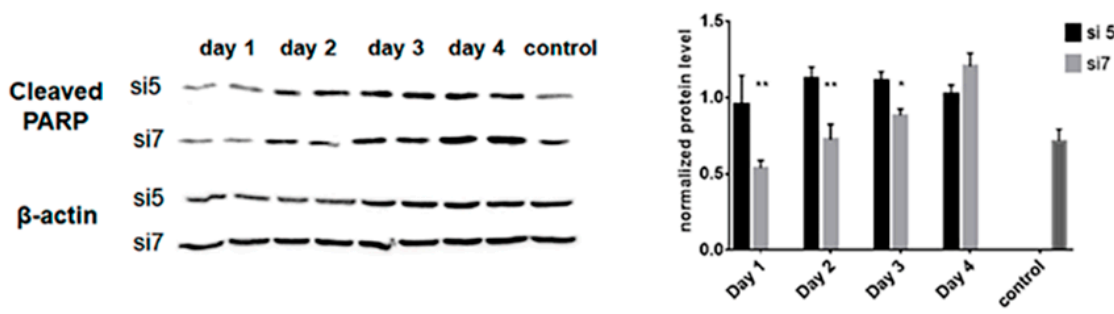

Figure 3. Analysis of Hepa1-6 cells after DDX3 knockdown in vitro. (A) Viability assay of DDX3 depleted cells using siRNA \#5 and \#7 at days 1, 2, 3 and 4 after initial siRNA transfection (normalized to control cells and viability at day 1). (B) Quantification of cleaved PARP in DDX3 KD hepatocytes at day 1, 2, 3 and 4 after initial siRNA transfection (normalized to control cells). ${ }^{*} p<0.05$, ${ }^{* *} p<0.01$. 
A.
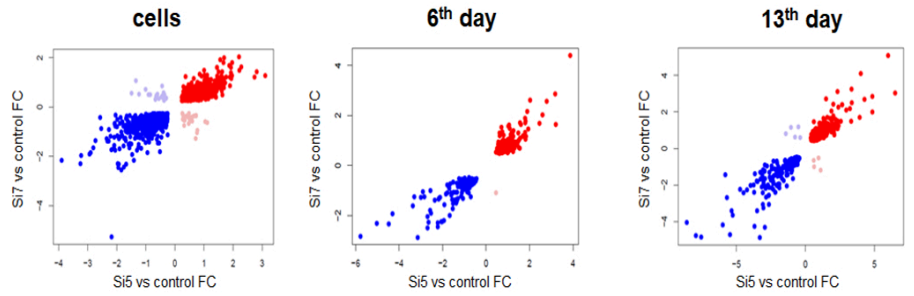

overlap
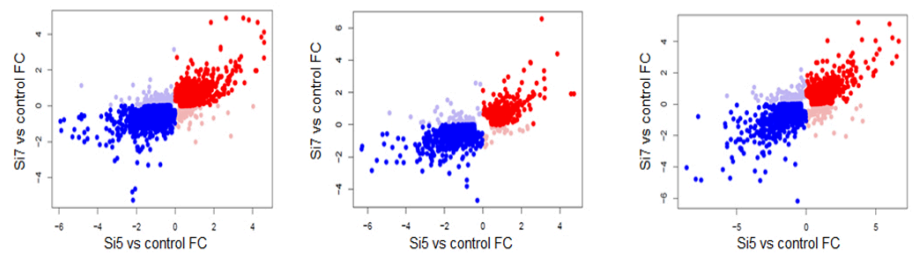

all

B.
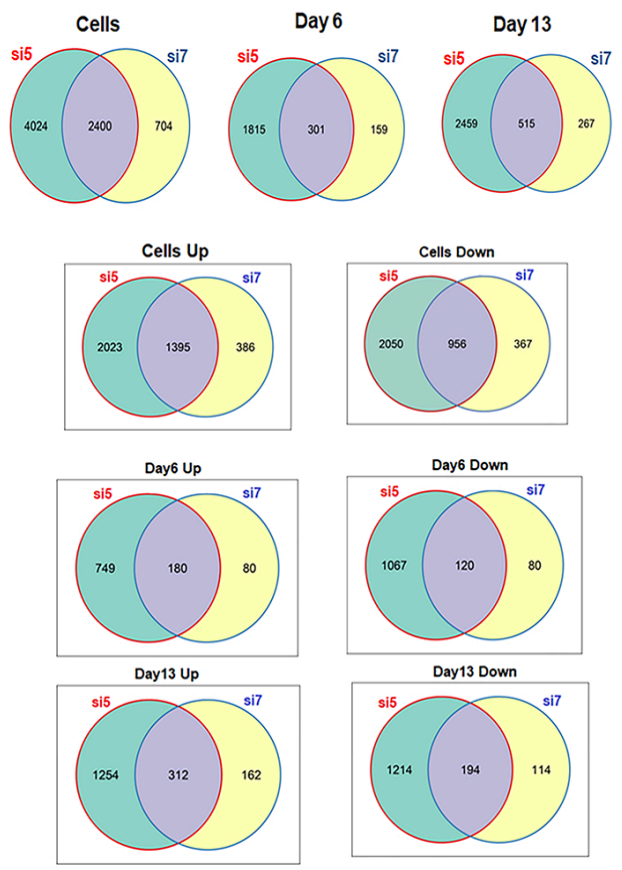

Figure 4. Comparison of differential gene expressions between DDX3 KD using siRNA \#5 and \#7 in hepatocytes in vitro, and in the liver at days 6 and 13 after LNP-siRNA delivery. (A) Scatterplots of the expression differences after siRNA\#5 and siRNA\#7 in comparison to controls (shown as log fold change). Dots represent individual genes that differ in both conditions. Colors indicate plot quadrants. (B) Venn diagram analysis of gene expression changes after DDX3 KD with either siRNA \#5 or \#7.

We analyzed changes in mRNA expression after siRNA \#5 administration in vitro and found 6424 changed mRNA in comparison to control siRNA (cutoff 2-fold, $p<0.05$ ), which included 3418 upregulated and 3006 downregulated ones (the list is shown in Supporting information). In the case of siRNA \#7 DDX3 KD in vitro, we found only 3104 changed mRNA in comparison to control siRNA, which included 1781 upregulated and 1323 downregulated ones. After administration of LNP-siRNA \#5 in vivo at day six, we found 2116 changed mRNA in comparison to control siRNA, among which 929 ones were upregulated and 1187 downregulated. At day 13. some increase was observed; the expressions of 2974 mRNA were changed in comparison with control siRNA, including 1566 upregulated and 1408 downregulated ones. After administration of LNP-siRNA \#7 in vivo at day six, only 460 mRNA were changed in comparison with control siRNA; among them, 260 were upregulated and 200 were downregulated. At day 13, some increase 
was observed: 782 mRNA were changed in comparison with control siRNA; 474 were upregulated and 308 downregulated. So, the use of more active siRNA \#5 to knockdown DDX3 in comparison to less effective siRNA \#7 led to changes in the expression of much more mRNA both in vitro and in vivo (Figure 4B). Based on the volcano plot data and exact mRNA with change expression, the phenotypes of murine livers with DDX3 KD inhibition significantly differed from hepatocytes in vitro (Supplementary Materials Figure S4A-C).

\subsection{GO Pathway Enrichment Analysis}

We performed PANTHER pathway enrichment analysis (http:/ / pantherdb.org/ (accessed on 16 February 2021)) of changed mRNA after DDX3 KD in vitro and in vivo. PANTHER is a database that combines gene functions, ontology, pathways and statistical analysis tools and allows enriched pathways for selected genes to be analyzed.

We found that knockdown of DDX3 mRNA in Hepa1-6 cells in vitro by siRNA \#5 caused similar changes as siRNA \#7 in the pathways determined by PANTHER. Among them were the Wnt, CCKR, EGF receptor, interleukin and cadherin signaling pathways (Figure 5).

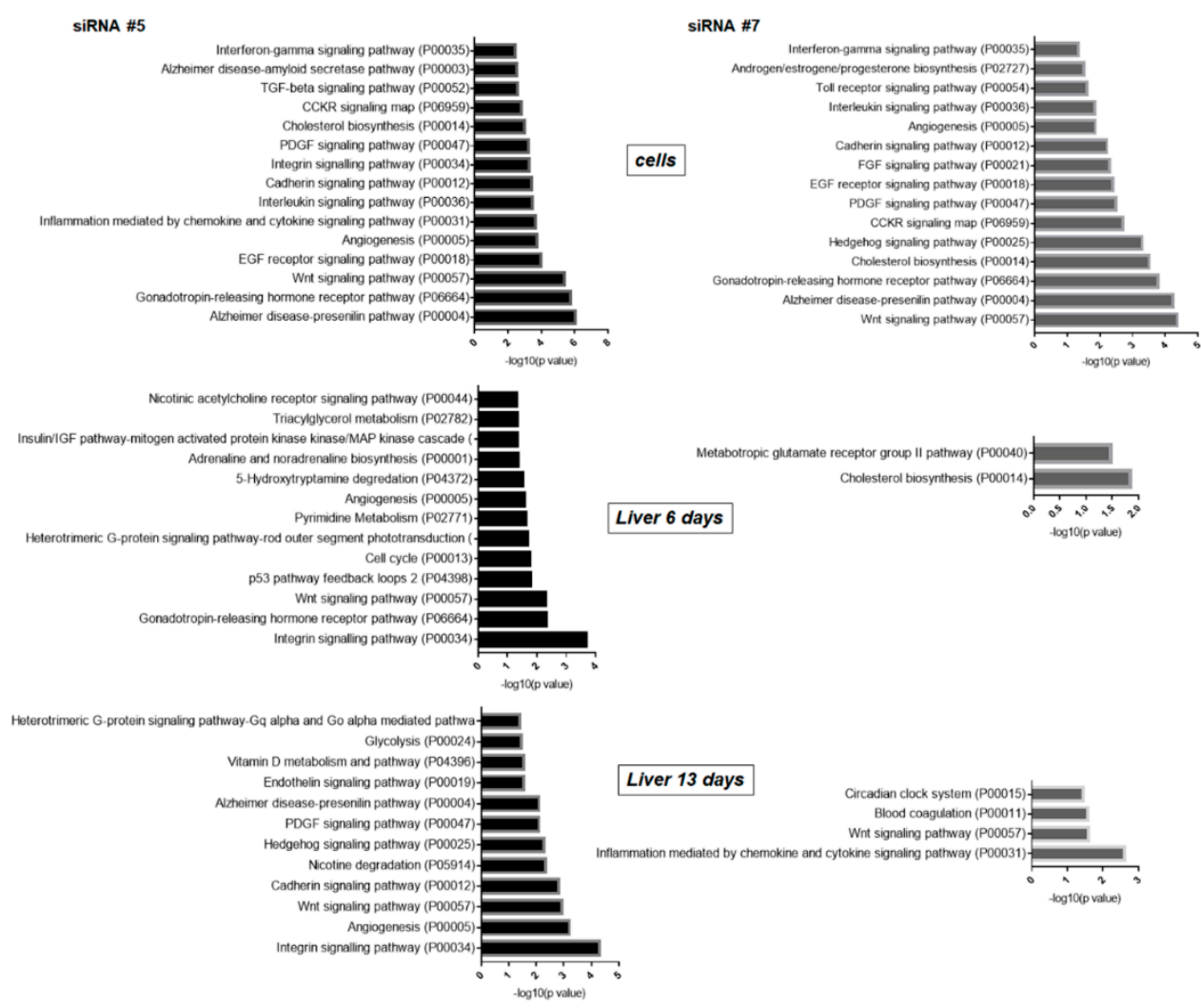

Figure 5. Top representative pathways obtained by PANTHER analysis of transcriptomes: DDX3 KD with siRNA \#5 and \#7 in hepatocytes in vitro, in the liver at days 6 and 13 after LNP-siRNA delivery.

The phenotype after DDX3 knockdown with siRNA \#7 in vivo differs a lot from the phenotype in vitro. At day six of DDX3 KD, less active siRNA \#7 caused reliable changes only in the biosynthesis of cholesterol and glutamate receptor group pathways. At day 13, we observed changes in Wnt and inflammation signaling pathways mediated by chemokine and cytokine. Administration of more active siRNA \#5 led to more significant changes in pathways, including Wnt, integrin, p53 and cell cycle at day six. To evaluate the obtained PANTHER pathways and confirm the transcriptome data, we performed RT-PCR analysis of the genes involved in cell cycle regulation, the Wnt signaling pathway and glucose and lipid metabolism after DDX3 KD in vitro and in vivo (Figure 6A). The observed changes correlate with the data from transcriptome analysis and additionally confirm the results of 
the PANTHER analysis. For additional investigation of the Wnt signaling pathway in vivo, we checked the phosphorylation level of $\beta$-catenin and found a decrease at day 13 in the murine liver after DDX3 KD (Figure 6B). Changes of $\beta$-catenin phosphorylation indicate the activation of the Wnt pathway.

A.
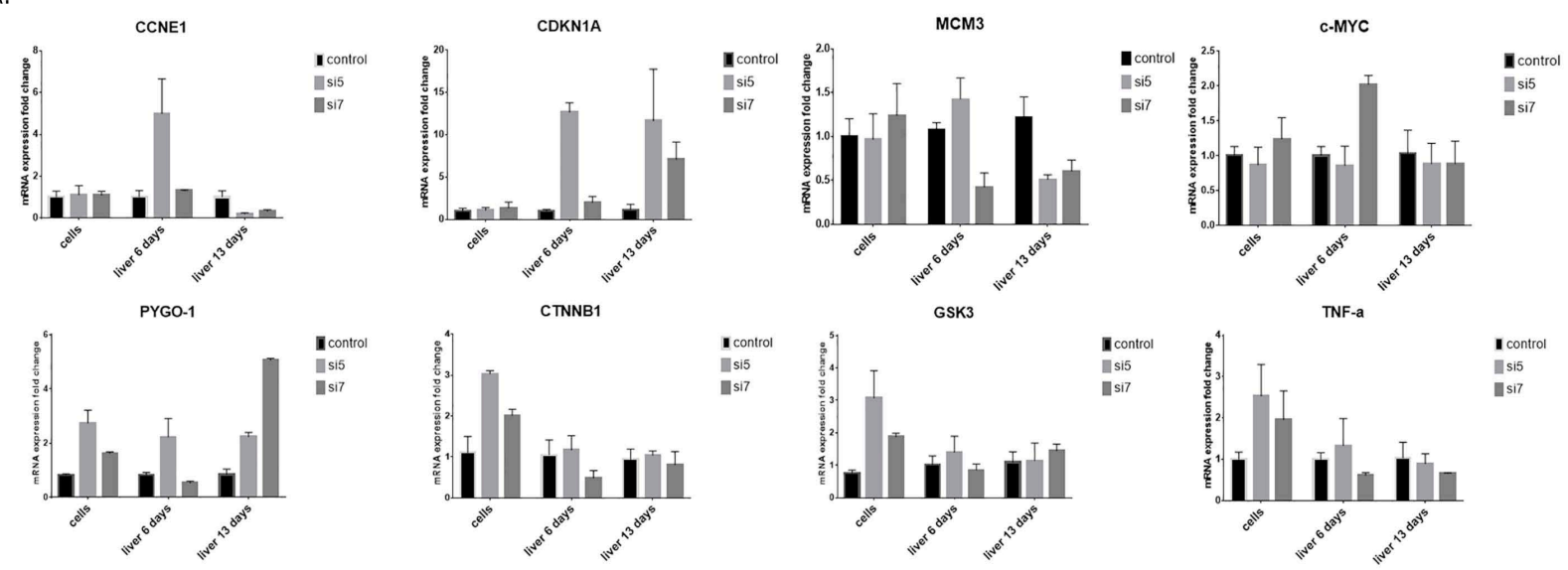

GSK3
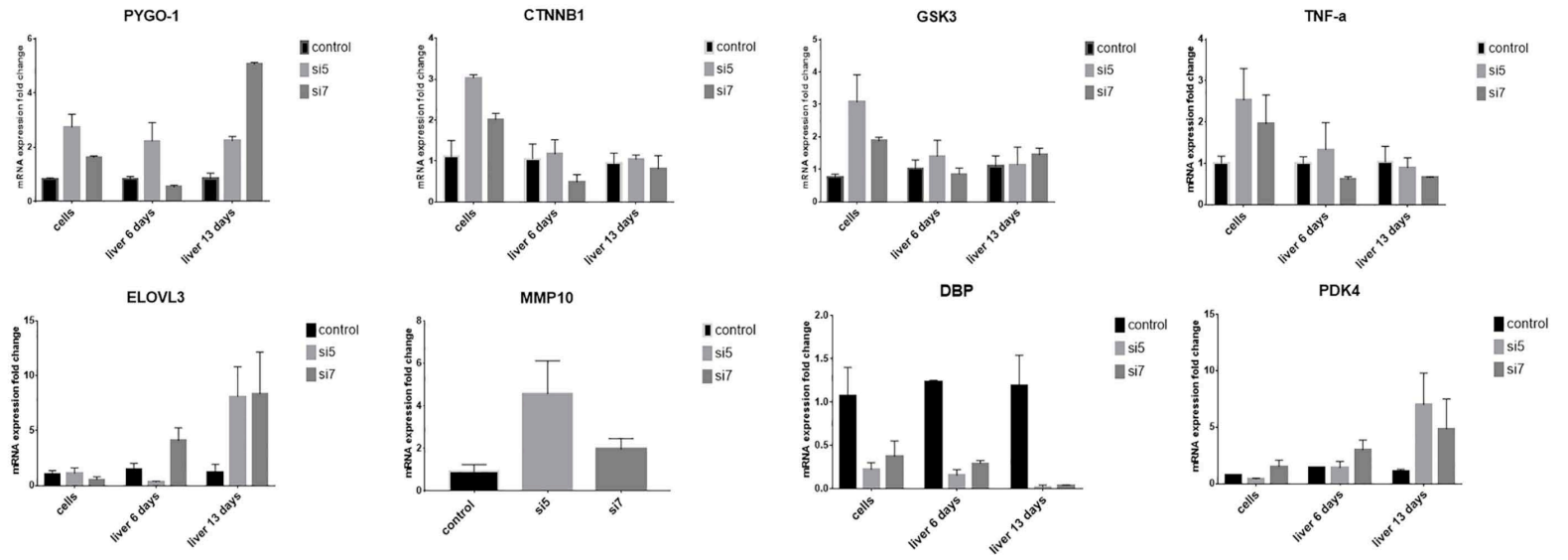

B.

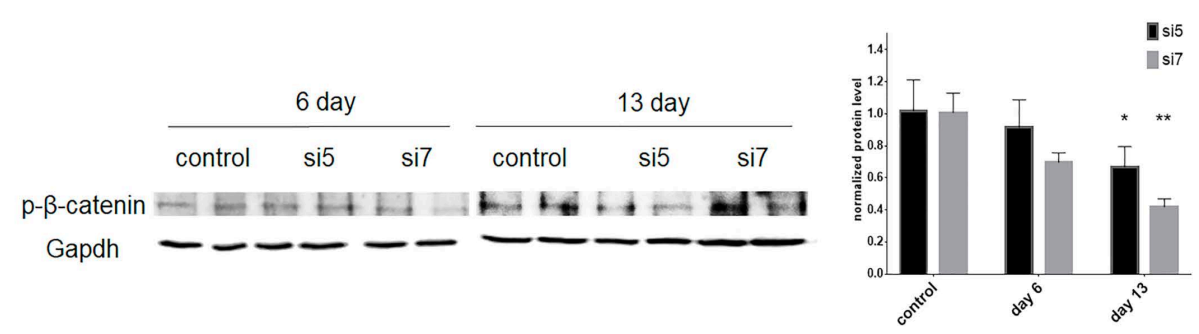

Figure 6. (A) Confirmation of the in vitro and in vivo transcriptome data by RT-qPCR after DDX3 KD with siRNA \#5 and \#7 by quantification of mRNA expression fold change in comparison with control siRNA. (B) Quantification of the b-catenin phosphorylation level in DDX3 KD in murine liver. Mmp10 mRNA was measured only in the cells. ${ }^{*} p<0.05,{ }^{* *} p<0.01$.

Prolonged siRNA \#5 action led to the activation of many cellular signaling pathways at day 13: integrin, Wnt, cadherin, Hedgehog, PDGF, endothelin and glycolysis. Based on these results, the phenotype in vivo after prolonged administration of more active siRNA \#5 (13 days) caused the same transcriptome changes of the pathways as both siRNAs in vitro. siRNA \#7 was less active in vivo and caused quite different phenotype changes (Figure 5).

Then we used gene ontology KEGG analysis, a common tool to study the functional relationship between gene products, and predicted three aspects: biological processes (BP), cellular components (CC) and molecular functions (MF) (Supplementary Materials Figure S5A-D). Analysis of in vitro and in vivo data shows high similarity to results obtained by the PANTHER tool. The phenotypes of siRNA \#5 and siRNA \#7 in the cells were similar and caused the same changes in BP, CC and MF. Hence, DDX3 knockdown in vivo differed a lot from siRNA \#7, which caused less significant changes in comparison to siRNA \#5. Prolonged administration of siRNA \#5 led to phenotype changes in vivo close to those in vitro. 


\section{Discussion}

DDX3 RNA helicase was intensively studied as a therapeutic target due to its contributions to the replication of viruses and cancer progression [52,53]. At the same time, DDX3 participates in almost all aspects of cell life, such as transcription [54-56], pre-mRNA splicing [57], mRNA translation [58-60], cell cycle regulation [61] and apoptosis [62]. As a result, there are reports that propose either oncogenic or tumor suppressor functions for DDX3 depending on the cancer, cell type or xenograft model used in the studies [57]. The small-molecule inhibitor of DDX3, RK-33, decreases the proliferation of multiple lung cancer cell lines in a dose-dependent manner and acts as a radiosensitizer in mouse models of lung cancer [29]. Bol et al. [28] demonstrated that changes in the human cancer lung cell line after RK-33 and shRNA-mediated DDX3 protein inhibition were similar: G1 cell cycle arrest, deregulation of Wnt pathway and induction of apoptosis. Also, after RK-33 administration in the xenograft murine model of prostate cancer, the level of caspase- 3 was increased and H\&E staining revealed increased cell death [29]. However, this result was obtained $24 \mathrm{~h}$ after RK33 administration and no data on the long-term treatment or the influence of DDX3 inhibition on healthy tissues was presented. Here, we addressed the safety issues of targeting DDX3 RNA helicase by a comparison of the gene expression in the cancer hepatocyte Hepa1-6 cell line and the liver of healthy mice after short and long-term DDX3 knockdown. We selected an RNAi-based approach because it can be applied both in vitro and in vivo and we can perform long-term downregulation of the target without significant toxicity and off-target effects. A number of siRNA drugs are already approved by the FDA and EMA, including patisiran [63], with siRNA embedded in lipid nanoparticles (LNP) for targeted delivery to the liver. We formulated active siRNAs in similar lipid nanoparticles for targeted delivery in the murine liver [42].

First, we selected potent and efficient siRNA (\#5 and \#7). They demonstrated similar activity in the cell line $(\sim 80 \%$ knockdown of DDX3 mRNA and protein; see Supplementary Materials Figure S1B,E), while in vivo we observed a significant difference for siRNA: \#5 was more active, while \#7 less active (Figure 1C). As the siRNA demonstrated close efficacy at day six and the most pronounced difference at day 13, we chose these timepoints for further morphological analysis and deep RNA sequencing of liver samples in comparison to controls and DDX3 knockdown Hepa1-6 cells in vitro. At day 13 of DDX3 knockdown, H\&E staining of the liver revealed infiltrated immune cells after administration of both siRNA \#5 and \#7 and the appearance of individual dying hepatocytes in the case of siRNA \#5 (Figure 2A). The appearance of individual apoptotic hepatocytes after long-term administration of the highly active siRNA \#5 confirms the damage to healthy cells. We additionally demonstrated the activation of caspase-3 cleavage after long-term administration of the most effective siRNA\#5 in vivo (Figure 2B). All these data correlate with the results demonstrated for RK-33 treatment [29].

Also, we checked the cell proliferation and protein level of cleaved PARP and found that more active siRNA \#5 caused a reduction in the proliferation and induction of apoptosis in vitro (Figure 3). This cellular phenotype after RNAi-mediated knockdown corresponds to the data obtained for the hepatocyte-specific DDX3 knockout mice [64]. We want to emphasize that after administration of siRNA \#7 with lower knockdown, similar effects were not observed. To compare changes in gene expression under these conditions, we performed transcriptome analysis of DDX3 knockdown Hepa1-6 cell in vitro and liver samples at days 6 and 13 of DDX3 KD to uncover dynamic response to varied levels of DDX3 protein.

As we expected, more active siRNA \#5 caused more significant changes in gene expression than siRNA \#7 both in vitro and in vivo (Figure 4). Gene function analysis with the PANTHER classification system of DDX3 knockdown in vitro demonstrated deregulation of many cell signaling pathways: EGF, cadherin, PDGF, cholesterol biosynthesis and Wnt (Figure 5). It was shown that DDX3 regulates cell migration and invasion through an E-cadherin mediated pathway $[65,66]$, is involved in the Wnt/ $\beta$-catenin signaling pathway and can affect the Wnt cascade [67]. In the case of cancerous cells, these changes 
are beneficial for treatment and correspond to the phenotype after DDX3 inhibition in different cell types [31,67-69]. However, DDX3 knockdown in vivo resulted in different changes in gene expression for siRNA \#5 and \#7. At day six (siRNA \#5), we observed differential expression of genes connected with the p53 pathway, integrin, cell cycle and Wnt pathways (top 5) (Figures 5 and 6) that correlates with our in vitro data and published data $[23,59,64,66,67,70]$. In the case of siRNA \#7, we can propose that $35-40 \%$ of the residual DDX3 protein is enough for normal cell functioning as only two pathways were changed in the murine liver. Long-term administration for 13 days of siRNA \#7 caused changes in the inflammation-mediated and Wnt pathways. Long-term administration of siRNA \#5 led to changes of gene expression in most cellular signaling pathways, which could be the result of multiple secondary effects (Figures 5 and 6).

Comparison of RNA levels (transcriptome data) between in vitro and in vivo studies can reveal discordant gene expression even under close conditions [71,72]. This difference may be determined by varied inhibition or downregulation of the target in these conditions. Organ or tissue homeostasis in vivo is more complex and includes immune responses, metabolic activation, hormone signaling and other regulatory events in comparison to common cell culture [73]. However, in the case of strong DDX3 KD, we got similar changes in PANTHER pathways in vitro and in vivo, and the phenotype after siRNA \#5-mediated DDX3 knockdown is similar to one observed after RK-33-mediated DDX3 inhibition [28,29]. Most of RK-33 studies were short-term and were done in cancer cells or xenograft mice models. Our results in the normal murine liver demonstrated that strong DDX3 knockdown (more than $80 \%$ ) caused changes in the main cellular pathways and finally led to the appearance of dying hepatocytes. Long-term treatment with less active siRNA \#7 did not cause such dramatic changes of the hepatocyte phenotype and cell death.

There are many examples when RNAi results in non-specific effects often referred to as off-target gene silencing [74,75]. Of course, a more reliable approach to confirm the knockdown data is one using multiple siRNAs. At the same time, this strategy can lead to the increase of non-specific effects, especially in the case of targets that participate in many biological processes in the cell. Previously, it was demonstrated that appropriate chemical modification and high efficacy of siRNA potently reduce potential off-targets [76,77]. In all investigations based on transient knockdown of mRNA, there is a probability of nonspecific effects, but if the obtained data correlate with each other and with the published data, we can conclude that most of them are reliable. The results for DDX3 KD are consistent with each other: the phenotype of the KD cell line was the same, and the changes of transcriptomes in vitro and in vivo were similar in biological processes for siRNA\#5. One more proof of reliability comes from similar transcriptome changes for siRNA\#7 KD in vivo. However, these changes were observed later (at day 13) and to a smaller extent. So, based on the data convergence coming from on-target-related changes in biological pathways using two siRNAs, we conclude that DDX3 protein contribution to various processes may depend on the level of the protein in the cell.

Here, we demonstrated protein level-dependent effects of DDX3 RNA helicase knockdown on the murine liver transcriptome. Strong downregulation of DDX3 led to the phenotype close to the published one, obtained with the small molecule inhibitor RK-33. However, these changes are beneficial only for cancer cells, while we found deregulation of many cellular processes and the appearance of the single dying hepatocytes in healthy livers. These follow-up events may be crucial for the successful development of therapeutics targeting the DDX3 RNA helicase. 
Supplementary Materials: The following are available online at https:/ /www.mdpi.com/article/ 10.3390/ijms22136958/s1.

Author Contributions: R.I., E.S., V.V. and O.S. performed experiments and analyzed and interpreted the data. T.A. performed LNP-siRNA injections and collected liver samples. I.K. performed bioinformatic analyses of transcriptomes. T.P. performed siRNA design and formulation in LNP. A.K. performed histology analysis. O.S. and T.Z. designed the research and wrote the manuscript. All authors have read and agreed to the published version of the manuscript.

Funding: This work was supported by the Russian Science Foundation (grant no. 19-74-00119 to O.S.).

Institutional Review Board Statement: The study was conducted according to the guidelines of the Regulations for Laboratory Practice in the Russian Federation, and approved by the Ethics Committee of Koltzov Institute of Developmental Biology RAS (protocol code 19 from 14.12.2017).

Informed Consent Statement: Not applicable.

Data Availability Statement: Publicly available datasets were analyzed in this study. This data can be found here: https: / / www.ncbi.nlm.nih.gov/geo/query / acc.cgi?acc=GSE178618 (accessed on 1 June 2021) (GEO accession GSE178618).

Acknowledgments: Library construction/sequencing was performed on the sequencing platform HiSeq 4000 (Illumina) using the resources of the Skoltech Genomics Core Facility.

Conflicts of Interest: The authors declare no conflict of interest.

\section{References}

1. Honek, J. Preclinical research in drug development. MEW 2017, 26, 5-8.

2. Polson, A.G.; Fuji, R.N. The successes and limitations of preclinical studies in predicting the pharmacodynamics and safety of cell-surface-targeted biological agents in patients. Br. J. Pharmacol. 2012, 166, 1600-1602. [CrossRef]

3. Pyle, A.M. Translocation and unwinding mechanisms of RNA and DNA helicases. Annu. Rev. Biophys. 2008, 37, 317-336. [CrossRef]

4. Heaton, S.M.; Atkinson, S.C.; Sweeney, M.N.; Yang, S.N.Y.; Jans, D.A.; Borg, N.A. Exportin-1-dependent nuclear export of DEAD-box helicase DDX3X is central to its role in antiviral immunity. Cells 2019, 8, 1181. [CrossRef]

5. Gaete-Argel, A.; Marques, C.; Barriga, G.; Soto-Rifo, R.; Valiente-Echeverria, F. Strategies for Success. Viral infections and membraneless organelles. Front. Cell Infect. Microbiol. 2019, 9, 236. [CrossRef] [PubMed]

6. Bourgeois, C.F.; Mortreux, F.; Auboeuf, D. The multiple functions of RNA helicases as drivers and regulators of gene expression. Nat. Rev. Mol. Cell. Biol. 2016, 17, 426-438. [CrossRef] [PubMed]

7. Khadivjam, B.; Stegen, C.; Hogue-Racine, M.-A.; el Bilali, N.; Döhner, K.; Sodeik, B.; Lippé, R. The ATP-dependent RNA Helicase DDX3X modulates herpes simplex virus 1 gene expression. J. Virol. 2017, 91, e02411-16. [CrossRef]

8. Fuller-Pace, F.; Nikol, S. DEAD-box RNA helicases as transcription cofactors. Methods Enzymol. 2012, 511, 347-367. [CrossRef] [PubMed]

9. Geissler, R.; Golbik, R.; Behrens, S. DEAD-box helicase DDX3 supports the assembly of functional 80S ribosomes. Nucl. Acids Res. 2012, 40, 4998-5011. [CrossRef] [PubMed]

10. Soto-Rifo, R.; Rubilar, P.; Limousin, T.; de Breyne, S.; Décimo, D.; Ohlmann, T. DEAD-box protein DDX3 associates with eIF4F to promote translation of selected mRNAs. EMBO J. 2012, 31, 3745-3756. [CrossRef]

11. Tsai, T.-Y.; Wang, W.-T.; Li, H.-K.; Chen, W.-J.; Tsai, Y.-H.; Chao, C.-H.; Lee, Y.-H.W. RNA helicase DDX3 maintains lipid homeostasis through upregulation of the microsomal triglyceride transfer protein by interacting with HNF4 and SHP. Sci. Rep. 2017, 7, 41452. [CrossRef]

12. Adjibade, P.; St-Sauveur, V.; Bergeman, J.; Huot, M.-E.; Khandjian, E.; Mazroui, R. DDX3 regulates endoplasmic reticulum stress-induced ATF4 expression. Sci. Rep. 2017, 7, 13832. [CrossRef] [PubMed]

13. Chen, W.-J.; Wang, W.-T.; Tsai, T.-Y.; Li, H.-K.; Lee, Y.-H.W. DDX3 localizes to the centrosome and prevents multipolar mitosis by epigenetically and translationally modulating p53 expression. Sci. Rep. 2017, 7, 9411. [CrossRef]

14. Taschuk, F.; Cherry, S. DEAD-box helicases: Sensors, regulators, and effectors for antiviral defense. Viruses $2020,12,181$. [CrossRef] [PubMed]

15. Lenarcic, E.M.; Ziehr, B.J.; Moorman, N.J. An unbiased proteomics approach to identify human cytomegalovirus RNA-associated proteins. Virology 2015, 481, 13-23. [CrossRef]

16. Yedavalli, V.S.R.K.; Neuveut, C.; Chi, Y.-H.; Kleiman, L.; Jeang, K.-T. Requirement of DDX3 DEAD box RNA helicase for HIV-1 Rev-RRE export function. Cell 2004, 119, 381-392. [CrossRef]

17. Owsianka, A.M.; Patel, A.H. Hepatitis C virus core protein interacts with a human DEAD box protein DDX3. Virology 1999, 257, 330-340. [CrossRef] [PubMed] 
18. Li, C.; Ge, L.; Li, P.; Wang, Y.; Dai, J.; Sun, M.; Huang, L.; Shen, Z.; Hu, X.; Ishag, H.; et al. Cellular DDX3 regulates Japanese encephalitis virus replication by interacting with viral un-translated regions. Virology 2014, 449, 70-81. [CrossRef]

19. Noble, C.G.; Chen, Y.-L.; Dong, H.; Gu, F.; Lim, S.P.; Schul, W.; Wang, Q.-Y.; Shi, P.-Y. Strategies for development of Dengue virus inhibitors. Antiviral Res. 2010, 85, 450-462. [CrossRef]

20. Brai, A.; Fazi, R.; Tintori, C.; Zamperini, C.; Bugli, F.; Sanguinetti, M.; Stigliano, E.; Esté, J.; Badia, R.; Franco, S.; et al. Human DDX3 protein is a valuable target to develop broad spectrum antiviral agents. Proc. Natl. Acad. Sci. USA 2016, 113, 5388-5393. [CrossRef]

21. Chahar, H.S.; Chen, S.; Manjunath, N. P-body components LSM1, GW182, DDX3, DDX6 and XRN1 are recruited to WNV replication sites and positively regulate viral replication. Virology 2013, 436, 1-7. [CrossRef]

22. Vashist, S.; Urena, L.; Chaudhry, Y.; Goodfellow, I. Identification of RNA-protein interaction networks involved in the Norovirus life cycle. J. Virol. 2012, 86, 11977-11990. [CrossRef] [PubMed]

23. Stunnenberg, M.; Geijtenbeek, T.; Gringhuis, S. DDX3 in HIV-1 infection and sensing: A paradox. Cytokine Growth Factor Rev. 2018, 40, 32-39. [CrossRef] [PubMed]

24. Yedavalli, V.S.R.K.; Zhang, N.; Cai, H.; Zhang, P.; Starost, M.F.; Hosmane, R.S.; Jeang, K.-T. Ring expanded nucleoside analogues inhibit RNA helicase and intracellular human immunodeficiency virus type 1 replication. J. Med. Chem. 2008, 51, 5043-5051. [CrossRef] [PubMed]

25. Shadrick, W.R.; Ndjomou, J.; Kolli, R.; Mukherjee, S.; Hanson, A.M.; Frick, D.N. Discovering new medicines targeting helicases: Challenges and recent Progress. J. Biomol. Screen. 2013, 18, 761-781. [CrossRef] [PubMed]

26. Radi, M.; Falchi, F.; Garbelli, A.; Samuele, A.; Bernardo, V.; Paolucci, S.; Baldanti, F.; Schenone, S.; Manetti, F.; Maga, G.; et al. Discovery of the first small molecule inhibitor of human DDX3 specifically designed to target the RNA binding site: Towards the next generation HIV-1 inhibitors. Bioorg. Med. Chem. Lett. 2012, 22, 2094-2098. [CrossRef] [PubMed]

27. Yang, S.N.Y.; Atkinson, S.C.; Audsley, M.D.; Heaton, S.M.; Jans, D.A.; Borg, N.A. RK-33 is a broad-spectrum antiviral agent that targets DEAD-Box RNA helicase DDX3X. Cells 2020, 9, 170. [CrossRef]

28. Bol, G.M.; Vesuna, F.; Xie, M.; Zeng, J.; Aziz, K.; Gandhi, N.; Levine, A.; Irving, A.; Korz, D.; Tantravedi, S.; et al. Targeting DDX3 with a small molecule inhibitor for lung cancer therapy. EMBO Mol. Med. 2015, 7, 648-669. [CrossRef]

29. Xie, M.; Vesuna, F.; Tantravedi, S.; Bol, G.M.; van Voss, M.R.H.; Nugent, K.; Malek, R.; Gabrielson, K.; van Diest, P.J.; Tran, P.T.; et al. RK-33 radiosensitizes prostate cancer cells by blocking the RNA Helicase DDX3. Cancer Res. 2016, 76, 6340-6350. [CrossRef]

30. Sergeeva, O.; Zatsepin, T. RNA Helicases as shadow modulators of cell cycle progression. Int. J. Mol. Sci. 2021, $22,2984$. [CrossRef]

31. Gopal, L.; Sapkota, P. Functions and regulation of the serine/threonine protein kinase CK1 family: Moving beyond promiscuity. Biochem. J. 2020, 447, 4603-4621. [CrossRef]

32. Fullam, A.; Gu, L.; Höhn, Y.; Schröder, M. DDX3 directly facilitates IKK $\alpha$ activation and regulates downstream signalling pathways. Biochem. J. 2018, 475, 3595-3607. [CrossRef]

33. Wang, X.; Wang, R.; Luo, M.; Li, C.; Wang, H.-X.; Huan, C.-C.; Qu, Y.-R.; Liao, Y.; Mao, X. (DEAD)-box RNA helicase 3 modulates NF- $\mathrm{KB}$ signal pathway by controlling the phosphorylation of PP2A-C subunit. Oncotarget 2017, 8, 33197-33213. [CrossRef] [PubMed]

34. Sun, M.; Zhou, T.; Jonasch, E.; Jope, R.S. DDX3 regulates DNA damage-induced apoptosis and p53 stabilization. Biochim. Biophys. Acta 2013, 1833, 1489-1497. [CrossRef] [PubMed]

35. Anderson, E.M.; Birmingham, A.; Baskerville, S.; Reynolds, A.; Maksimova, E.; Leake, D.; Fedorov, Y.; Karpilow, J.; Khvorova, A. Experimental validation of the importance of seed complement frequency to siRNA specificity. RNA 2008, 14, 853-861. [CrossRef]

36. Dong, Y.; Siegwart, D.; Anderson, D. Strategies, design and chemistry in siRNA delivery systems. Adv. Drug Deliv. Rev. 2019, 114, 133-147. [CrossRef]

37. Reynolds, A.; Leake, D.; Boese, Q.; Scaringe, S.; Marshall, W.S.; Khvorova, A. Rational siRNA design for RNA interference. Nat. Biotechnol. 2004, 22, 326-330. [CrossRef]

38. Pei, Y.; Tuschl, T. On the art of identifying effective and specific siRNAs. Nat. Methods 2006, 3, 670-676. [CrossRef]

39. Jackson, A.L.; Burchard, J.; Leake, D.; Reynolds, A.; Schelter, J.; Guo, J.; Johnson, J.M.; Lim, L.; Karpilow, J.; Nichols, K.; et al. Position-specific chemical modification of siRNAs reduces "off-target" transcript silencing. RNA 2006, 12, 1197-1205. [CrossRef]

40. Jayaraman, M.; Ansell, S.M.; Mui, B.L.; Tam, Y.K.; Chen, J.; Du, X.; Butler, D.; Eltepu, L.; Matsuda, S.; Narayanannair, J.K.; et al. Maximizing the potency of siRNA lipid nanoparticles for hepatic gene silencing in vivo. Angew. Chem. Int. Ed. Engl. 2012, 51, 8529-8533. [CrossRef]

41. Walsh, C.; Ou, K.; Belliveau, N.M.; Leaver, T.J.; Wild, A.W.; Huft, J.; Lin, P.J.; Chen, S.; Leung, A.K.; Lee, J.B.; et al. Microfluidicbased manufacture of siRNA-lipid nanoparticles for therapeutic applications. Methods Mol. Biol. 2014, 1141, 109-120. [CrossRef] [PubMed]

42. Roces, C.; Lou, G.; Jain, N.; Abraham, S.; Thomas, A.; Halbert, G.; Perrie, Y. Manufacturing considerations for the development of lipid nanoparticles using microfluidics. Pharmaceutics 2020, 12, 1095. [CrossRef] [PubMed]

43. Dobin, A.; Davis, C.; Schlesinger, F.; Drenkow, J.; Zaleski, C.; Jha, S.; Batut, P.; Chaisson, M.; Gingeras, T. STAR: Ultrafast universal RNA-seq aligner. Bioinformatics 2013, 29, 15-21. [CrossRef]

44. Love, M.; Huber, W.; Anders, S. Moderated estimation of fold change and dispersion for RNA-seq data with DESeq2. Genome Biol. 2014, 15, 550. [CrossRef] [PubMed] 
45. Leek, J.T. svaseq: Removing batch effects and other unwanted noise from sequencing data. Nucl. Acids Res. 2014,42, e161. [CrossRef]

46. Yu, G.; Wang, L.-G.; Han, Y.; He, Q.-Y. clusterProfiler: An R package for comparing biological themes among gene clusters. OMICS 2012, 16, 284-287. [CrossRef]

47. Shah, A.; Rashid, F.; Awan, H.M.; Hu, S.; Wang, X.; Chen, L.; Shan, G. The DEAD-Box RNA helicase DDX3 interacts with m6A RNA demethylase ALKBH5. Stem Cells Int. 2017, 2017, e8596135. [CrossRef]

48. Kasim, V.; Wu, S.; Taira, K.; Miyagishi, M. Determination of the Role of DDX3 a factor involved in mammalian RNAi pathway using an shRNA-expression library. PLoS ONE 2013, 8, e59445. [CrossRef]

49. Su, C.-Y.; Lin, T.-C.; Lin, Y.-F.; Chen, M.-H.; Lee, C.-H.; Wang, H.-Y.; Lee, Y.-C.; Liu, Y.-P.; Chen, C.-L.; Hsiao, M. DDX3 as a strongest prognosis marker and its downregulation promotes metastasis in colorectal cancer. Oncotarget 2015, 6, 18602-18612. [CrossRef]

50. Love, K.T.; Mahon, K.P.; Levins, C.G.; Whitehead, K.A.; Querbes, W.; Dorkin, J.R.; Qin, J.; Cantley, W.; Qin, L.L.; Racie, T.; et al. Lipid-like materials for low-dose, in vivo gene silencing. Proc. Natl. Acad. Sci. USA 2010, 107, 1864-1869. [CrossRef]

51. Bogorad, R.L.; Yin, H.; Zeigerer, A.; Nonaka, H.; Ruda, V.M.; Zerial, M.; Anderson, D.G.; Koteliansky, V. Nanoparticle-formulated siRNA targeting integrins inhibits hepatocellular carcinoma progression in mice. Nat. Commun. 2014, 5, 3869. [CrossRef]

52. Valiente-Echeverría, F.; Hermoso, M.; Soto-Rifo, R. RNA helicase DDX3: At the crossroad of viral replication and antiviral immunity. Rev. Med. Virol. 2015, 25, 286-299. [CrossRef] [PubMed]

53. Garbelli, A.; Radi, M.; Falchi, F.; Beermann, S.; Zanoli, S.; Manetti, F.; Dietrich, U.B.M.; Maga, G. Targeting the human DEAD-Box polypeptide 3 (DDX3) RNA helicase as a novel strategy to inhibit viral replication. Curr. Med. Chem. 2011, 18, 3015-3027. [CrossRef] [PubMed]

54. Schröder, M.; Baran, M.; Bowie, A.G. Viral targeting of DEAD box protein 3 reveals its role in TBK1/IKKepsilon-mediated IRF activation. EMBO J. 2008, 27, 2147-2157. [CrossRef] [PubMed]

55. Chao, C.-H.; Chen, C.-M.; Cheng, P.-L.; Shih, J.-W.; Tsou, A.-P.; Lee, Y.-H.W. DDX3, a DEAD box RNA helicase with tumor growthsuppressive property and transcriptional regulation activity of the p21waf1/cip1 promoter, is a candidate tumor suppressor. Cancer Res. 2006, 66, 6579-6588. [CrossRef]

56. Botlagunta, M.; Vesuna, F.; Mironchik, Y.; Raman, A.; Lisok, A.; Winnard, P.; Mukadam, S.; van Diest, P.; Chen, J.H.; Farabaugh, P.; et al. Oncogenic role of DDX3 in breast cancer biogenesis. Oncogene 2008, 27, 3912-3922. [CrossRef]

57. Fuller-Pace, F.V. DEAD box RNA helicase functions in cancer. RNA Biol. 2013, 10, 121-132. [CrossRef]

58. Shih, J.-W.; Tsai, T.-Y.; Chao, C.-H.; Lee, Y.-H.W. Candidate tumor suppressor DDX3 RNA helicase specifically represses cap-dependent translation by acting as an eIF4E inhibitory protein. Oncogene 2008, 27, 700-714. [CrossRef] [PubMed]

59. Ariumi, Y. Multiple functions of DDX3 RNA helicase in gene regulation, tumorigenesis, and viral infection. Front. Genet. 2014, 5, 423. [CrossRef]

60. Hilliker, A.; Gao, Z.; Jankowsky, E.; Parker, R. The DEAD-box protein Ded1 modulates translation by the formation and resolution of an eIF4F-mRNA complex. Mol. Cell. 2011, 43, 962-972. [CrossRef]

61. van Voss, M.R.H.; Kammers, K.; Vesuna, F.; Brilliant, J.; Bergman, Y.; Tantravedi, S.; Wu, X.; Cole, R.N.; Holland, A.; van Diest, P.J.; et al. Global effects of DDX3 inhibition on cell cycle regulation identified by a combined phosphoproteomics and single cell tracking approach. Transl. Oncol. 2018, 11, 755-763. [CrossRef] [PubMed]

62. Sun, M.; Song, L.; Li, Y.; Zhou, T.; Jope, R. Identification of an antiapoptotic protein complex at death receptors. Cell Death Differ. 2008, 15, 1887-1900. [CrossRef] [PubMed]

63. Adams, D.; Gonzalez-Duarte, A.; O’Riordan, W.D.; Yang, C.; Ueda, M.; Kristen, A.; Tournev, I.; Schmidt, H.; Coelho, T.; Berk, J.; et al. Patisiran an RNAi therapeutic, for hereditary transthyretin amyloidosis. N. Engl. J. Med. 2018, 379, 11-21. [CrossRef] [PubMed]

64. Chan, C.-H.; Chen, C.-M.; Lee, Y.-H.W.; You, L.-R. DNA damage, liver injury, and tumorigenesis: Consequences of DDX3X loss. Mol. Cancer Res. 2019, 17, 555-566. [CrossRef] [PubMed]

65. Zhao, L.; Mao, Y.; Zhou, J.; Zhao, Y.; Cao, Y.; Chen, X. Multifunctional DDX3: Dual roles in various cancer development and its related signaling pathways. Am. J. Cancer Res. 2016, 6, 387-402.

66. Chen, H.-H.; Yu, H.-I.; Cho, W.-C.; Tarn, W.-Y. DDX3 modulates cell adhesion and motility and cancer cell metastasis via Rac1-mediated signaling pathway. Oncogene 2015, 34, 2790-2800. [CrossRef]

67. Cruciat, C.-M.; Dolde, C.; de Groot, R.E.A.; Ohkawara, B.; Reinhard, C.; Korswagen, H.C.; Niehrs, C. RNA helicase DDX3 is a regulatory subunit of casein kinase 1 in Wnt- $\beta$-catenin signaling. Science 2013, 339, 1436-1441. [CrossRef] [PubMed]

68. van Voss, M.R.H.; Vesuna, F.; Trumpi, K.; Brilliant, J.; Berlinicke, C.; de Leng, W.; Kranenburg, O.; Offerhaus, J.G.; Bürger, H.; van der Wall, E.; et al. Identification of the DEAD box RNA helicase DDX3 as a therapeutic target in colorectal cancer. Oncotarget 2015, 6, 28312-28326. [CrossRef] [PubMed]

69. Tarn, W.-Y.; Chang, T.-H. The current understanding of Ded1p/DDX3 homologs from yeast to human. RNA Biol. 2009, 6, 17-20. [CrossRef]

70. He, Y.; Zhang, D.; Yang, Y.; Wang, X.; Zhao, X.; Zhang, P.; Zhu, H.; Xu, N.; Liang, S. A double-edged function of DDX3, as an oncogene or tumor suppressor, in cancer progression. Oncol. Rep. 2018, 39, 883-892. [CrossRef] 
71. Kulthong, K.; Hooiveld, G.J.E.J.; Duivenvoorde, L.; Estruch, I.M.; Marin, V.; van der Zande, M.; Bouwmeester, H. Transcriptome comparisons of in vitro intestinal epithelia grown under static and microfluidic gut-on-chip conditions with in vivo human epithelia. Sci. Rep. 2021, 11, 3234. [CrossRef]

72. Ord, J.J.; Streeter, E.H.; Roberts, I.S.D.; Cranston, D.; Harris, A.L. Comparison of hypoxia transcriptome in vitro with in vivo gene expression in human bladder cancer. Br. J. Cancer 2005, 93, 346-354. [CrossRef] [PubMed]

73. Pang, G.; Xie, J.; Chen, Q.; Hu, Z. Energy intake, metabolic homeostasis, and human health. FSHW 2014, 3, 89-103. [CrossRef]

74. Putzbach, W.; Gao, Q.; Patel1, M.; Haluck-Kangas, A.; Murmann, A.; Peter, M. DISE: A seed dependent RNAi off-target effect that kills cancer cells. Trends Cancer 2018, 4, 10-19. [CrossRef]

75. Bartoszewski, R.; Sikorski, A. Editorial focus: Understanding off-target effects as the key to successful RNAi therapy. Cell Mol. Biol. Lett. 2019, 24, 69. [CrossRef] [PubMed]

76. Jackson, A.; Linsley, P. Recognizing and avoiding siRNA off-target effects for target identification and therapeutic application. Nat. Rev. Drug Discov. 2010, 9, 57-67. [CrossRef] [PubMed]

77. Janas, M.; Schlegel, M.; Harbison, C.; Yilmaz, V.; Jiang, Y.; Parmar, R.; Zlatev, I.; Castoreno, A.; Xu, H.; Shulga-Morskaya, S.; et al. Selection of GalNAc-conjugated siRNAs with limited off-target-driven rat hepatotoxicity. Nat. Commun. 2018, 9, 723. [CrossRef] [PubMed] 